\title{
A Pilot Study of Home Treatment of Deep Vein Thrombosis With Subcutaneous Once-Daily Enoxaparin Plus Warfarin
}

\author{
BEVERLY BISHOP, PharmD, MS; ANDREW G. WILSON, JR., MD, FACEP; \\ DOUGLAS POST, RPh; LAUREEN HOWARD, BSN, RN, MSA; and LAWRENCE RUEHLEN, RN
}

\begin{abstract}
OBJECTIVE: To evaluate patient satisfaction, effectiveness, and safety of at-home treatment of acute deep vein thrombosis (DVT) with subcutaneous enoxaparin dosed at $1.5 \mathrm{mg} / \mathrm{kg}$ once daily plus oral warfarin.

METHODS: Patients with acute DVT and no more than 1 previous episode of DVT received enoxaparin plus oral warfarin until their international normalized ratio (INR) was $>2$ on 2 consecutive days. Patients were recruited between November 2000 and June 2003, and a home-care nurse visited the patient daily to administer the enoxaparin and to perform a fingerstick INR test. Patients received warfarin at doses adjusted to maintain an INR in the range of 2 to 3 . Efficacy and safety were assessed daily by a home-care nurse and then by telephone interview conducted by a pharmacist at 14,30 , and 90 days during follow-up. Patient satisfaction with treatment was assessed by a verbal questionnaire.

RESULTS: There were 52 patients enrolled. The mean duration of enoxaparin home treatment was 4.5 days, and the mean INR on discontinuation of enoxaparin was 2.73. Most patients (84.6\%) had INRs within the desired therapeutic range (INR value 2-3); no patient had a subtherapeutic INR. There were no symptoms of recurrent venous thromboembolism reported. Major bleeding occurred 7 days after discontinuation of enoxaparin in one patient with impending surgery for removal of a uterine tumor. There were 2 cases of minor bleeding. The patient satisfaction questionnaire revealed that patients considered home treatment to be acceptable. The average cost savings was $\$ 2,925$ per patient compared with typical inpatient treatment with unfractionated heparin.
\end{abstract}

CONCLUSION: The results of this pilot study suggest that home treatment with initial once-daily enoxaparin in conjunction with long-term oral warfarin is a safe and effective alternative to inpatient therapy with once-daily enoxaparin or unfractionated heparin for select patients with acute DVT. Cost savings are derived from the substitution of inpatient care with home care.

KEYWORDS: Outpatients, Home treatment, Enoxaparin, Deep vein thrombosis, Thromboembolism

J Manag Care Pharm. 2006;12(1):70-75 $\square$ eep vein thrombosis (DVT) affects approximately 1 of every 2,000 people in the general population each year in the United States ${ }^{1,2}$ and is a major cause of mortality and morbidity because of the risk of complications such as pulmonary embolism (PE) and postthrombotic syndrome. The economic costs and the inconvenience to the patient of in-hospital treatment of DVT create a strong rationale for safe and effective home anticoagulant therapy in eligible patients.

Traditionally, the treatment of DVT involved unfractionated heparin (UFH) administered intravenously in a hospital setting for 5 to 7 days. ${ }^{3}$ However, the use of UFH requires hospitalization for close monitoring because of the narrow therapeutic index and a nonlinear dose-response relationship that shows marked variation between individuals. ${ }^{3,4}$ By contrast, low-molecularweight heparins (LMWHs) offer a more predictable pharmacokinetic profile and anticoagulant effect and can be administered by subcutaneous injection without routine anticoagulation monitoring. ${ }^{5}$ Several studies have shown that LMWHs are at least as effective as intravenous (IV) UFH in the in-hospital treatment of DVT. ${ }^{6-8}$ Furthermore, the ability to administer LMWHs subcutaneously makes it feasible to treat patients in their home, rather than in the hospital. Although treatment in an outpatient setting offers the benefits of convenience for the patient and the potential to reduce hospital costs, ${ }^{9-13}$ many physicians may be reluctant to use this approach, possibly because of a belief that the controlled conditions of clinical trials are not representative of the real-world clinical situation. While large randomized trials have shown that twice-daily LMWH treatment at home is effective and well tolerated compared with UFH treatment in the hospital, ${ }^{14-16}$ less data are available to support once-daily dosage of enoxaparin on an outpatient basis. ${ }^{17,18}$

We carried out a pilot study in patients with acute DVT to evaluate the convenience, efficacy, and safety of the LMWH enoxaparin, $1.5 \mathrm{mg} / \mathrm{kg}$, given once daily in a real-world U.S. patient population eligible for home treatment.

BEVERLY BISHOP, PharmD, MS, is a clinical pharmacist, Saint Joseph's Health System, Clinton Township, Michigan; ANDREW G. WILSON, JR., MD, FACEP, is chief, emergency medicine, and chairman emeritus, and DOUGLAS POST, $R P h$, is a clinical pharmacist, Department of Pharmacy Services, both at William Beaumont Hospital, Royal Oak, Michigan; LAUREEN HOWARD, BSN, RN, MSA, is director, William Beaumont Homecare, Royal Oak, Michigan; LAWRENCE RUEHLEN, RN, is a home care nurse.

AUTHOR CORRESPONDENCE: Beverly Bishop, PharmD, MS, Clinical Pharmacist, Saint Joseph's Health System, 15855 Nineteen Mile Rd., Clinton Township, MI, 48038. Tel: (586) 263 2650; Fax: (586) 263 2569;

E-mail:bishobp@trinity-health.org

Copyright $\odot$ 2006, Academy of Managed Care Pharmacy. All rights reserved.

\section{Methods}

The study was a prospective, nonrandomized, open-label study performed at a single center in the United States enrolling patients eligible for home care with LMWH. William Beaumont Hospital is a 1,085-bed community, nonprofit, teaching hospital located in Royal Oak, Michigan. The study was conducted according to the Declaration of Helsinki and approved by the hospital's Institutional Review Board. Written informed consent was obtained from all patients before inclusion in the study. 
Patients were enrolled between November 2000 and June 2003. Adult patients with acute proximal DVT confirmed by Doppler ultrasound were eligible for the study if they met the eligibility criteria for home therapy summarized in Table 1. Patients were recruited from the emergency room, a short-stay ambulatory unit, and inpatient areas of the hospital. Baseline laboratory assessment included serum creatinine, hemoglobin, platelets, and prothrombin time. On the day of hospital discharge, all patients were administered a single subcutaneous (SC, $1.5 \mathrm{mg} / \mathrm{kg}$ ) dose of enoxaparin (Lovenox). Prior to discharge, patients were provided with a 7-day supply of enoxaparin and 25 tablets of $2.5 \mathrm{mg}$ warfarin (Coumadin). Patients or their caregivers were educated by a pharmacist prior to discharge and by the home care nurse at the first visit. Education included the purpose of anticoagulant therapy, anticoagulant monitoring, and signs and symptoms of adverse events, with a signed educational checklist added to the inclusion criteria to ensure that each patient was fully informed.

Initially, patients received enoxaparin $1.5 \mathrm{mg} / \mathrm{kg} \mathrm{SC}$ once daily, administered by a home-care nurse, and daily oral warfarin dosage titrated by a pharmacist. The international normalized ratio (INR) was monitored every 1 to 3 days by fingerstick testing (CoaguChek, Roche Diagnostics), and the warfarin dose was adjusted until the target range (2-3) was recorded for 2 consecutive days. Daily nursing visits ceased when a second INR was verified to be in the therapeutic range (with no enoxaparin administered on the final day of home nursing visits). Warfarin treatment was then continued with INR monitoring done by venous draw (not fingerstick) and dose adjustment was at the discretion of the patient's private physician and not recorded for the study. Adherence to warfarin therapy was confirmed by telephone follow-up at 14, 30, and 90 days. To document cases of readmission, hospital computer records were checked and patients were questioned at the follow-up intervals to ensure that readmission to another institution would be reported.

Efficacy and safety were assessed daily during enoxaparin treatment and at 14, 30, and 90 days during follow-up warfarin therapy. Assessments were made by telephone interviews using a questionnaire to confirm the absence of signs or symptoms of thromboembolism (PE or DVT), bleeding, or other adverse events. Efficacy outcome was the absence of repeat thromboembolic symptoms. For example, patients were asked whether the lower limb pain or swelling had changed (which could indicate worsening of the DVT) or if they had experienced any shortness of breath or chest pain (which could indicate progression of DVT to PE). Safety outcomes were signs or symptoms of any adverse events, including bleeding, allergy, or death. For example, patients were asked whether they had any nosebleeds, bruising, rashes, or blood in stools, urine, or the mouth. A major bleed was defined as a drop in hemoglobin of $>2 \mathrm{~g} / \mathrm{dL}$ or evidence of any intracranial bleed or retroperitoneal bleed.

\section{TABLE 1 Inclusion and Exclusion Criteria for Outpatient Treatment of DVT}

Inclusion criteria:

- Age $\geq 18$ years

- Diagnosis of DVT confirmed by ultrasound

- Are medically stable and otherwise ready for discharge

- Suitable home environment with supportive care and phone

- Ability to understand and sign consent form and educational assessment*

Exclusion criteria (excluded: $\mathrm{n}=128$ )

- Other bleeding and/or hematological disorders (e.g., coagulopathy;

hemoglobin $<11 \mathrm{~g} / \mathrm{dL}$ in men or $<9 \mathrm{~g} / \mathrm{dL}$ in women;

platelets $<100$ cells $/ \mathrm{mm}^{3}$ ) $[44] \dagger$

- Renal failure (e.g., creatinine clearance $<30 \mathrm{~mL} / \mathrm{min}$ ) [32]

- $\geq 2$ previous episodes of DVT [22]

- Surgery in last 2 weeks [13]

- Acute PE or clot with ileo-caval involvement [9]

- Total body weight $>150 \%$ of lean body weight [5]

- Pregnancy [2]

- Concurrent epidural analgesia [1]

- Recent history of bleeding, PE, or peptic ulcer in last 2 weeks [0]

- Hypertension (e.g., >180 mm Hg systolic or >110 mm Hg diastolic blood pressure over 24 hours) [0]

- Heparin-associated antibody [0]

* An educational checklist was signed by the patient or caregiver to ensure that there was adequate education provided regarding the purpose of anticoagulant therapy, anticoagulant monitoring, and signs and symptoms of adverse events.

$\uparrow$ Numbers in brackets after criteria indicate the number of patients exlcuded because of that criteria.

$D V T=$ deep vein thrombosis; $P E=$ pulmonary embolism.

TABLE 2 Baseline Patient Characteristics $(n=52)$

\begin{tabular}{l|c}
\hline Characteristic & Number (\%) \\
\hline Enrolled as inpatients started on UFH & 32 \\
\hline Enrolled directly from emergency room & 20 \\
\hline Age, years $( \pm$ SD) & $58( \pm 14.2)$ \\
\hline Weight, $\mathrm{kg}( \pm$ SD) & $88.3( \pm 18.3)$ \\
\hline Male, $\mathrm{n}(\%)$ & $38(73.1)$ \\
\hline Receiving concomitant therapy: & $8(15.4)$ \\
Aspirin & $1(1.9)$ \\
Clopidogrel & $2(3.8)$ \\
Ibuprofen & $2(3.8)$ \\
Allopurinol &
\end{tabular}

UFH=unfractionated heparin.

A secondary outcome was the number of days required to reach the INR target.

Patient satisfaction with treatment was assessed during follow-up by means of a questionnaire consisting of 3 questions:

1 . Were you satisfied with the pain control?

2. Were you satisfied with the nursing visits?

3. Were you satisfied with the fingerstick INR blood test method? 


\begin{tabular}{|c|c|}
\hline inding & Number \\
\hline $\begin{array}{l}\text { lean number of outpatient days } \\
\text { reach therapeutic INR }( \pm \text { SD) }\end{array}$ & $\begin{array}{c}4.5( \pm 2.1) \\
\text { (range, } 1-12 \text { days) }\end{array}$ \\
\hline reatment duration (doses) $( \pm \mathrm{SD})$ & $4.5( \pm 2.1)$ \\
\hline lean INR at LMWH discontinuation $( \pm$ SD) & $2.73 \pm 0.74$ \\
\hline atients at therapeutic INR at LMWH discontinuation (\%) & $44(84.6 \%)$ \\
\hline $\begin{array}{l}\text { atients at supratherapeutic INR (>3) } \\
\text { t LMWH discontinuation }(\%)\end{array}$ & $8(15.4 \%)$ \\
\hline atients with major bleeding (\%) & $1(1.9 \%)^{*}$ \\
\hline atients with minor bleeding (\%) & $2(3.8 \%)$ \\
\hline \multicolumn{2}{|c|}{$\begin{array}{l}\text { One patient was lost to follow-up, withdrawn from study at day } 13 \text { because of } \\
\text { impending surgery. } \\
\text { NR=international normalized ratio (therapeutic INR }=2.0 \text { to } 3.0 \text { ); } \\
M W H=\text { low-molecular-weight heparin. }\end{array}$} \\
\hline
\end{tabular}

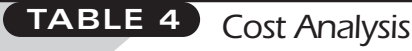

\begin{tabular}{l|c}
\hline Therapy & Costs (\$) \\
\hline Outpatient DVT treatment daily costs: & 85 \\
Medications (enoxaparin)* & 118 \\
Home nursing & 30 \\
Laboratory fees & 233 \\
Outpatient total cost per day & \\
\hline Inpatient DVT treatment daily costs: & 3 \\
Medications (UFH)* & 880 \\
Inpatient bed cost and monitoring & 883 \\
Inpatient total cost per day & 14 \\
\hline Medication costs for treatment duration†: & 383 \\
UFH & 369 \\
Enoxaparin & 3,974 \\
Cost increase for pharmacy for enoxaparin vs. UFH & 1,049 \\
\hline Total cost of therapy for treatment duration $\dagger:$ & 2,925 \\
UFH in-hospital & \\
Enoxaparin in-home & \\
Cost saving of outpatient therapy & \\
* Medication costs were based on average wholesale price during the study period; \\
enoxaparin cost was based on average dose for the study group (120 mg). \\
+ Duration of therapy was based on an average of 4.5 days to therapeutic inter- \\
national normalized ratio; billed charges for inpatient and home nursing visits \\
were based on average annual rates during the study period (November 2000- \\
September 2003), which ranged from an estimated \$700 to \$900 for inpatient \\
room and board (estimate obtained from chief financial officer) and $\$ 96$ to $\$ 126$ \\
per day for home nursing care visits over this nearly 4-year period. \\
DVT=deep vein thrombosis; UFH=unfractionated heparin. \\
\hline
\end{tabular}

Only descriptive statistics were used in this study.

For the same study period, billing and payment data for daily home nursing visits were recorded for enrolled patients. The patient or third-party payer was billed for the number of visits, and the payment was recorded.

\section{Results}

Of 233 patients screened for enrollment, 53 declined participation (through either the patient or primary care physician), and 128 were excluded by the exclusion criteria (Table 1). The reason(s) for ineligibility were: low hemoglobin or platelet count (44), creatinine clearance $<30 \mathrm{~mL} / \mathrm{min}$ (32), $\geq 2$ DVT by history (22), recent surgery (13), PE or clot with ileo-caval involvement (9), total body weight greater than $150 \%$ of lean body weight (5), pregnancy (2), and spinal epidural (1). Patient demographics are shown in Table 2. A total of 52 patients were recruited, of whom 32 were inpatients started on UFH (average UFH treatment duration $3.25 \pm 1.93$ days), and 20 (38\%) presented to the emergency room but were not subsequently admitted for inpatient care. Of the recruited patients, 51 completed the study; 1 patient was removed on physician advice due to hemorrhage at a uterine tumor site that resulted in surgery prior to further DVT treatment. For those patients receiving concomitant therapy with aspirin, clopidogrel, ibuprofen or allopurinol $(n=13)$, none noted bleeding.

Efficacy and safety outcomes are summarized in Table 3. The mean duration of enoxaparin treatment was 4.5 days, equating to 4.5 doses of enoxaparin when allowing for the dose on discharge from hospital and no dose given on the final day of home-care visits. The mean INR at the time of enoxaparin discontinuation was 2.73; a total of 44 patients (84.6\%) had INRs within the therapeutic range, and, of the remaining patients, all had supratherapeutic INRs $(>3)$.

There were no reports of symptoms that could indicate recurrent DVT or PE during the study. Major bleeding, resulting in a 3.6-g/dL decrease in hemoglobin concentration, occurred in one patient $(1.9 \%)$ who subsequently underwent removal of a uterine tumor on day 13 of warfarin treatment ( 7 days after discontinuation of enoxaparin). This patient was withdrawn from the study due to impending surgery. This patient was the only readmission to the hospital identified in the study. There were $2(3.8 \%)$ cases of minor bleeding: at the injection site in one patient and scleral hemorrhage in the other patient.

The 3-item patient satisfaction questionnaire, for which there was a $100 \%$ response rate, revealed that patients considered home treatment to be convenient. All 52 patients reported that they were satisfied with their pain control and understood the methods to reduce leg pain (i.e., they verbalized that raising the leg or taking acetaminophen were sufficient measures for relief). The fingerstick method of blood monitoring (compared with conventional venous blood sampling) was satisfactory to all patients, and 22 patients (42\%) expressed an interest in continuing this method, had it been made available, after the home-care nurse was discontinued because it was "less painful" and "less invasive" than the venous method. Forty-seven patients (90.4\%) were satisfied with the home-care nursing visits.

Of the 45 patients for whom cost data were recorded (limited by availability of records in 7 cases), there were 4.3 daily home 
visits at a billed charge per visit of $\$ 118 \pm 9.7$. The overall cost for home-care treatment was compared with the cost for typical inpatient UFH treatment over the same study period. The average savings were $\$ 2,925$ per patient despite higher pharmacy costs (Table 4). Average reimbursement for home nursing visits was $90 \%$ of billed charges $(\$ 457 \pm 187)$.

\section{Discussion}

The results of this pilot study suggest that once-daily treatment with enoxaparin at a dose of $1.5 \mathrm{mg} / \mathrm{kg}$, delivered at home in conjunction with long-term therapy with warfarin, is convenient, effective, and safe for the treatment of eligible patients with DVT. Patients considered at high risk were excluded from the present study. Compared with previous practice in this medical center, inpatient hospital days were either decreased or avoided. In the present study, there were no episodes of recurrent DVT symptoms, no symptoms of PE, and no serious adverse events related to enoxaparin. The one case of major bleeding occurred in a patient with a uterine tumor with impending surgery for its removal, and the bleeding was not considered related to enoxaparin.

These results are consistent with those of recent randomized comparative trials (Table 5) in which outpatient treatment with SC enoxaparin, either once or twice daily, was as effective as in-hospital treatment with IV UFH. ${ }^{14,17,18}$ This observational study adds to the accumulating evidence to support the use of outpatient enoxaparin once daily and is in accord with a recent position statement encouraging the development and documentation of outpatient DVT treatment programs. ${ }^{13}$

Once-daily administration offers obvious advantages over twice-daily treatment in terms of greater convenience for both patients and nursing staff. This greater convenience was reflected in the high levels of patient satisfaction reported in this study. Moreover, the reduced number of hospital visits required with once-daily treatment at home offers potential savings in the costs of nursing staff, drugs, and consumables. ${ }^{9-11}$ Such savings are due largely to reductions in costs associated with hospitalization. In the present study, outpatient treatment of DVT with enoxaparin once daily provided $74 \%$ lower costs when compared retrospectively with typical inpatient UFH therapy for the same treatment duration (Table 4). The average saving of $\$ 2,925$ per patient was realized despite higher pharmacy costs.

A prior retrospective analysis of average length of stay in those patients receiving UFH at our hospital found that, for the period 1998-2000, 165 patients were hospitalized for an average 5.5 days (range, 3-9). Therefore, the savings in actual practice may be larger and will certainly be different in other medical centers. In addition, the actual payer costs may be higher or lower than our findings since reimbursement for home nursing visits in the present analysis was approximately $90 \%$ of billed charges.

Thus, the data suggest that at-home treatment in select

\begin{tabular}{|c|c|c|c|c|}
\hline & $\begin{array}{l}\text { Present } \\
\text { Study }\end{array}$ & $\begin{array}{c}\text { Chong et al. } \\
2005^{17}\end{array}$ & $\begin{array}{c}\text { Ramacciotti et al. } \\
2004^{18}\end{array}$ & $\begin{array}{c}\text { Levine et al. } \\
1996^{14}\end{array}$ \\
\hline No. of patients & 52 & $\begin{array}{c}\text { Enoxaparin } \\
150 \text { vs. } \\
\text { UFH } 148 \\
(\mathrm{n}=298)\end{array}$ & $\begin{array}{c}\text { Enoxaparin } \\
104 \text { vs. } \\
\text { UFH } 97 \\
(\mathrm{n}=201)\end{array}$ & $\begin{array}{c}\text { Enoxaparin } \\
247 \text { vs. } \\
\text { UFH } 253 \\
(n=500)\end{array}$ \\
\hline Treatment & $\begin{array}{c}\text { Once-daily } \\
\text { enoxaparin } \\
1.5 \mathrm{mg} / \mathrm{kg}\end{array}$ & $\begin{array}{c}\text { Once-daily } \\
\text { enoxaparin } \\
1.5 \mathrm{mg} / \mathrm{kg} \\
\text { vs. UFH }\end{array}$ & $\begin{array}{c}\text { Once-daily } \\
\text { enoxaparin } \\
1.5 \mathrm{mg} / \mathrm{kg} \\
\text { vs. UFH }\end{array}$ & $\begin{array}{c}\text { Twice-daily } \\
\text { enoxaparin } \\
1 \mathrm{mg} / \mathrm{kg} \\
\text { vs. UFH }\end{array}$ \\
\hline Study design & $\begin{array}{c}\text { Prospective, } \\
\text { open label, } \\
\text { without a } \\
\text { control group } \\
\text { (1 center) }\end{array}$ & \begin{tabular}{|c|} 
Randomized \\
parallel- \\
group, \\
open-label \\
(18 centers)
\end{tabular} & $\begin{array}{l}\text { Randomized, } \\
\text { controlled, } \\
\text { open-label } \\
\text { (13 centers) }\end{array}$ & $\begin{array}{l}\text { Randomized } \\
\text { open-label } \\
\text { (14 centers) }\end{array}$ \\
\hline $\begin{array}{l}\text { Follow-up } \\
\text { (days) }\end{array}$ & 90 & 180 & $90-180$ & 90 \\
\hline $\begin{array}{l}\text { Incidence of } \\
\text { major bleeding }\end{array}$ & $1.9 \%$ & $0 \% *$ & $\begin{array}{c}1.9 \% \\
\text { enoxaparin } \\
(\mathrm{n}=2) \\
\text { UFH }(\mathrm{n}=3)\end{array}$ & $\begin{array}{c}2.0 \% \\
\text { enoxaparin } \\
(\mathrm{n}=5) \\
\text { UFH }(\mathrm{n}=3)\end{array}$ \\
\hline $\begin{array}{l}\text { Overall } \\
\text { incidence of } \\
\text { DVT } \\
\text { enoxaparin } \\
\text { vs. UFH }\end{array}$ & $0 \%$ & $\begin{array}{c}3.66 \% * \\
\text { enoxaparin } \\
1.6 \% \\
(\mathrm{n}=2) \\
\text { UFH } 5.4 \% \\
(\mathrm{n}=8)\end{array}$ & $\begin{array}{c}3.48 \% \\
\text { enoxaparin } \\
1 \% \\
(\mathrm{n}=1) \\
\text { UFH 6\% } \\
(\mathrm{n}=6)\end{array}$ & $\begin{array}{c}6 \% \\
\text { enoxaparin } \\
5.3 \% \\
(\mathrm{n}=13) \\
\text { UFH 6.7\% } \\
(\mathrm{n}=17)\end{array}$ \\
\hline $\begin{array}{l}\text { ncidence of } \\
\text { hospital } \\
\text { eadmission }\end{array}$ & $1.9 \%$ & N/A & N/A & $\mathrm{N} / \mathrm{A}$ \\
\hline
\end{tabular}

* 150 enoxaparin patients were evaluated for bleeding as a result of follow-up phone calls to patients; however, only 125 patients were evaluable for recurrent DVT because 20 had no efficacy assessment at 24 weeks, 6 received treatment for fewer than 5 days, and 3 did not satisfy entry criteria. The combined end point of $D V T+P E$ was $2.7 \%$ for enoxaparin versus $8.8 \%$ for $U F H(P=0.026 \%)$

$D V T=$ deep vein thrombosis; $P E=$ pulmonary embolism; $N / A=$ not available; $U F H=$ unfractionated heparin.

patients is a cost-effective alternative to hospitalization. This is supported by a previous study in which outpatient treatment with LMWH reduced the number of hospital days by $40 \%$ (7.2 vs. 12.1 days for UFH) and total treatment costs by $64 \%$ compared with UFH. ${ }^{9}$ Compared with UFH, LMWH treatment has been shown to produce cost savings when as few as $8 \%$ of patients with DVT were treated as outpatients. ${ }^{10}$ Moreover, studies comparing outpatient and inpatient treatment with LMWHs have shown that outpatient treatment can result in cost savings of up to $82 \% .^{11,19}$ Lee et al. reported in 1996 that the outpatient treatment of DVT with LMWH reduced the mean patient treatment cost from $\$ 3,266$ to $\$ 584$, a cost that included medications, 
laboratory analyses, and home visits or hospital days as appropriate. ${ }^{11}$ Tillman et al. found that an outpatient program carried out in a health maintenance organization, enrolling 391 patients treated with initial enoxaparin and warfarin to 90 days, realized total cost savings of $\$ 1,108,587$ over the 2-year evaluation period. ${ }^{20}$

For patients with acute DVT, the American College of Chest Physicians (ACCP) recommends initial treatment with SC LMWH once or twice daily over UFH, as an outpatient if possible, or as an inpatient if necessary. ${ }^{21}$ Yet, despite the accumulating evidence for the safety and cost-effectiveness of at-home treatment with LMWHs, there appears to be some reluctance among physicians to use such therapy. More than $80 \%$ of patients with DVT have been shown to be eligible for outpatient treatment, ${ }^{22,23}$ yet one recent study reported that only $20 \%$ of the patients diagnosed with DVT received treatment with LMWH in an outpatient setting. ${ }^{24}$ This may reflect physician concerns over the patient's ability to learn a new therapy (for self-administration) or the perceived lack of direct supervision by health care professionals. It may also reflect a view that findings from clinical trials, conducted under controlled conditions with multiple inclusion/exclusion criteria, are not necessarily applicable to the real-world patient population found in clinical practice..$^{25}$ Thus real-world studies, such as the one presented here, can provide important insights into the potential benefits of once-daily at-home treatment with LMWH for eligible patients.

Physician acceptance of at-home treatment appeared to improve during the course of this pilot study. Physicians began to contact the investigator to enroll patients and, in some cases, sent patients to the emergency room for consideration for home care as a substitute for hospital admission. This has particular significance given that DVT has traditionally been perceived by physicians as a serious condition requiring hospitalization. Furthermore, in the early stages of this pilot study, the daily patient assessments by the home-care nurse helped convince the physicians of the safety of home treatment, such that toward the end of patient enrollment, physicians were suggesting that patients be taught to self-inject enoxaparin to avoid the need for nursing visits. This could be explored further in future studies. While the home-care nurse confirmed compliance with the medications, it may be beneficial to study daily compliance in patients trained to self-inject enoxaparin.

\section{Limitations}

Foremost among the limitations of this study is the lack of a UFH comparison arm with patients matched for disease severity. This limits clinical interpretation of our data and more robust cost-savings analysis. Second, the relatively small sample size and exclusion of high-risk patients limit the generalization of these results to all patients with DVT. Third, assessment of DVT recurrence was based on patient self-assessment and was not subject to objective screening. Fourth, the questionnaire used in this study was intended as an indicator of patient satisfaction and did not provide a validated quality-of-life assessment or quantitative measure of patient satisfaction. Further studies examining the service/humanistic outcomes of care for DVT would be of value in supporting once-daily home management of DVT.

\section{Conclusion}

Initial once-daily enoxaparin administered in the home with concurrent warfarin appears to provide efficacious and safe care in eligible patients with acute DVT. Home treatment with enoxaparin offers the opportunity to reduce the cost of treating DVT, without compromising clinical outcomes, and may be associated with patient satisfaction with care. This was a pilot study, and the favorable clinical and service/humanistic outcomes observed should be assessed with more quantitative measures by other researchers.

\section{ACKNOWLEDGMENTS}

The authors acknowledge the technical assistance of Holly J. Kershaw, pharmacy technician, Pharmacy Department, William Beaumont Hospital, Royal Oak, Michigan, and Rachel McCarthy, PhD, program manager, Global Medical Communications, Excerpta Medica, Amsterdam, The Netherlands, in the preparation of this article.

\section{DISCLOSURES}

Funding for this study was provided by sanofi-aventis and administered through the Beaumont Research Institute; it was obtained by authors Beverly Bishop and Andrew G. Wilson, Jr. Wilson and authors Douglas Post, Laureen Howard, and Lawrence Ruehlen are employees of the William Beaumont health care system. The authors disclose no potential bias or conflict of interest relating to this article. Bishop served as principal author of the study. Study concept and design were contributed by all authors. Data collection and data interpretation were primarily the work of Bishop, with input from the co-authors. Drafting of the manuscript and its revision were the work of all authors.

\section{REFERENCES}

1. Silverstein MD, Heit JA, Mohr DN, et al. Trends in the incidence of deep vein thrombosis and pulmonary embolism: a 25 -year population-based study. Arch Intern Med. 1998;158:585-93.

2. Anderson FA Jr, Wheeler HB, Goldberg RJ, et al. A population-based perspective of the hospital incidence and case-fatality rates of deep vein thrombosis and pulmonary embolism. The Worcester DVT Study. Arch Intern Med. 1991;151:933-38.

3. Hirsh J. Heparin. N Engl J Med. 1991;324:1565-74.

4. Hirsh J, van Aken WG, Gallus AS, et al. Heparin kinetics in venous thrombosis and pulmonary embolism. Circulation. 1976;53:691-95.

5. Hirsh J, Warkentin TE, Shaughnessy SG, et al. Heparin and low-molecularweight heparin: mechanisms of action, pharmacokinetics, dosing, monitoring, efficacy, and safety. Chest. 2001;119(suppl 1):64S-94S

6. Hull RD, Raskob GE, Pineo GF, et al. Subcutaneous low-molecular-weight heparin compared with continuous intravenous heparin in the treatment of proximal-vein thrombosis. N Engl J Med. 1992;326:975-82.

7. A randomised trial of subcutaneous low molecular weight heparin (CY 216) compared with intravenous unfractionated heparin in the treatment of deep vein thrombosis. A collaborative European multicentre study. Thromb Haemost. 1991;65:251-56.

8. Prandoni P, Lensing AW, Büller HR, et al. Comparison of subcutaneous lowmolecular-weight heparin with intravenous standard heparin in proximal deep-vein thrombosis. Lancet. 1992;339:441-45. 
9. van den Belt AG, Bossuyt PM, Prins MH, et al. Replacing inpatient care by outpatient care in the treatment of deep venous thrombosis: an economic evaluation. TASMAN Study Group. Thromb Haemost. 1998;79:259-63.

10. Gould MK, Dembitzer AD, Sanders GD, et al. Low-molecular-weight heparins compared with unfractionated heparin for treatment of acute deep venous thrombosis. A cost-effectiveness analysis. Ann Intern Med. 1999;130: 789-99.

11. Lee M, Pao D, Hsu T, et al. Cost-savings and effectiveness of outpatient treatment with low molecular weight heparin of deep vein thrombosis in a community hospital. Can J Clin Pharmacol. 2004;11:e17-27 [Epub April 1, 2004].

12. O’Brien B, Levine M, Willan A, Goeree R. Economic evaluation of outpatient treatment with low-molecular-weight heparin for proximal vein thrombosis. Arch Intern Med. 1999;159:2298-2304.

13. ASHP therapeutic position statement on the use of low-molecular-weight heparins for adult outpatient treatment of acute deep-vein thrombosis. Am J Health Syst Pharm. 2004;61:1950-55.

14. Levine M, Gent M, Hirsh J, et al. A comparison of low-molecular-weight heparin administered primarily at home with unfractionated heparin administered in the hospital for proximal deep-vein thrombosis. N Engl J Med. 1996; 334:677-81

15. Koopman MM, Prandoni P, Piovella F, et al. Treatment of venous thrombosis with intravenous unfractionated heparin administered in the hospital as compared with subcutaneous low-molecular-weight heparin administered at home. The Tasman Study Group. N Engl J Med. 1996;334:682-87.

16. The Columbus Investigators. Low-molecular-weight heparin in the treatment of patients with venous thromboembolism. N Engl J Med. 1997;337:657-62.

17. Chong BH, Brighton TA, Baker RI, et al. for the ASTH DVT Study Group. Once-daily enoxaparin in the outpatient setting versus unfractionated heparin in hospital for the treatment of symptomatic deep-vein thrombosis. J Thromb Thrombolysis. 2005;19(3):173-81.
18. Ramacciotti E, Araújo GR, Lastoria S, et al. An open-label, comparative study of the efficacy and safety of once-daily dose of enoxaparin versus unfractionated heparin in the treatment of proximal lower limb deep-vein thrombosis. Thromb Res. 2004;114:149-53.

19. Boccalon H, Elias A, Chalé JJ, et al. Clinical outcome and cost of hospital vs. home treatment of proximal deep vein thrombosis with a low-molecularweight heparin: the Vascular Midi-Pyrenees study. Arch Intern Med. 2000;160: 1769-73.

20. Tillman DJ, Charland SL, Witt DM. Effectiveness and economic impact associated with a program for outpatient management of acute deep vein thrombosis in a group model health maintenance organization. Arch Intern Med. 2000;160:2926-32

21. Büller HR, Agnelli G, Hull RD, et al. Antithrombotic therapy for venous thromboembolic disease: the Seventh ACCP Conference on Antithrombotic and Thrombolytic Therapy. Chest. 2004;126(suppl 3):401S-28S.

22. Wells PS, Kovacs MJ, Bormanis J, et al. Expanding eligibility for outpatient treatment of deep vein thrombosis and pulmonary embolism with low-molecular-weight heparin: a comparison of patient self-injection with homecare injection. Arch Intern Med. 1998;158:1809-12.

23. Harrison L, McGinnis J, Crowther M, et al. Assessment of outpatient treatment of deep-vein thrombosis with low-molecular-weight heparin. Arch Intern Med. 1998;158:2001-3.

24. Goldhaber SZ, Tapson VF. A prospective registry of 5,451 patients with ultrasound-confirmed deep vein thrombosis. Am J Cardiol. 2004;93:259-62.

25. McAlister FA. Applying evidence to patient care: from black and white to shades of grey. Ann Intern Med. 2003;138:938-99. 